\title{
Hubungan Merokok dan Obesitas Sentral dengan Nilai Ankle-Brachial Index pada Mahasiswa Fakultas Kedokteran Universitas Sam Ratulangi
}

\author{
Maghfirah Savitri, ${ }^{1}$ Frans Wantania, ${ }^{2}$ Bisuk P. Sedli ${ }^{2}$
}

\author{
${ }^{1}$ Program Studi Pendidikan Dokter Fakultas Kedokteran Universitas Sam Ratulangi Manado \\ ${ }^{2}$ Bagian Ilmu Penyakit Dalam Fakultas Kedokteran Universitas Sam Ratulangi Manado \\ Email: maghfirahsav@gmail.com
}

\begin{abstract}
Peripheral artery disease (PAD) is commonly found in the community but it is hard to detect in primary health care providers. Smoking and central obersity are the major risk factors in the development of PAD. One non-invasive and cheap method in screening for PAD is determining the ankle-brachial index (ABI). This study was aimed to provide an overview of the relationship between ABI and smoking and central obesity among students of Faculty of Medicine, Sam Ratulangi University. This was an analytical study with a cross sectional design using the ABI results of the students. There were 73 students as subjects; 26 non-smokers with no central obesity (36\%), 15 smokers (20\%), 21 with central obesity (29\%), and 11 smokers with central obesity (15\%). The age range of subjects was 18-23 year olds (young adult age). The Fisher's exact test analysis of the relationship between smoking and PAD obtained a p-value of $0.267(\mathrm{p}>\alpha=0.05)$ and of the relationship between central obesity and PAD obtained a p-value of $0.016(\mathrm{p}<\alpha=0.05)$. In conclusion, there was a significant relationship between central obesity and $\mathrm{ABI}$, albeit there was no significant relationship between smoking and $\mathrm{ABI}$.
\end{abstract}

Keywords: peripheral artery disease, ankle-brachial index, smoking, central obesity.

\begin{abstract}
Abstrak: Penyakit arteri perifer (PAP) banyak ditemukan pada masyarakat tetapi sulit terdeteksi di layanan kesehatan primer. Merokok dan obesitas sentral ialah faktor risiko yang berperan penting dalam perkembangan PAP. Salah satu metode pemeriksaan non invasif, murah, dan mudah untuk mendeteksi PAP ialah dengan menentukan nilai Ankle-Brachial Index (ABI). Penelitian ini bertujuan untuk mengetahui gambaran ABI serta hubungan merokok dan obesitas sentral dengan PAP pada mahasiswa Fakultas Kedokteran Universitas Sam Ratulangi. Jenis penelitian ialah analitik dengan desain potong lintang menggunakan hasil pemeriksaan ABI. Hasil penelitian mendapatkan 73 mahasiswa sebagai subyek; 26 yang tidak merokok dan tidak obes sentral (36\%), 15 yang merokok (20\%), 21 yang obes sentral (29\%), dan 11 yang obes sentral dan merokok (15\%). Kisaran usia sampel yaitu 18-23 tahun (usia dewasa muda). Hasil uji Fisher's exact terhadap hubungan merokok dengan PAP didapatkan nilai $p=0,269(p>\alpha=0,05)$ dan untuk obesitas sentral dengan PAP didapatkan nilai $\mathrm{p}=0,016(\mathrm{p}<\alpha=0,05)$. Simpulan penelitian ini ialah terdapat hubungan bermakna antara obesitas dengan nilai ABI, tetapi tidak terdapat hubungan bermakna antara merokok dengan nilai ABI.
\end{abstract}

Kata kunci: penyakit arteri perifer, ankle-brachial index, merokok, obesitas sentral

\section{PENDAHULUAN}

Gaya hidup masyarakat saat ini sangat memungkinkan bagi mereka untuk menderita penyakit sistemik. Obesitas sentral dan merokok menjadi faktor risiko kuat terjadinya aterosklerosis. Penyakit arteri perifer (PAP) merupakan manifestasi dari aterosklerosis. ${ }^{1}$ Penyakit arteri perifer juga merupakan salah satu penyakit yang banyak ditemukan pada masyarakat dan 
sulit terdeteksi di layanan kesehatan primer. $^{2}$

Salah satu metode pemeriksaan non invasif, murah dan mudah untuk mendeteksi PAP ialah dengan menentukan nilai ankle-brachial index (ABI). ${ }^{2}$ Nilai anklebrachial index tinggi tidak hanya ditemukan pada laki-laki, pasien diabetes melitus (DM), dan hipertensi, tetapi juga pada individu yang merokok dan dislipidemia. ${ }^{1}$ Penyakit arteri perifer perlu untuk dilakukan deteksi dini karena 50\% kasus PAP ditemukan asimtomatik. ${ }^{3}$

Pada penelitian tahun 2018 didapatkan lebih dari 200 juta orang di seluruh dunia menderita PAP, dari yang asimtomatik hingga dengan gejala berat. Secara umum terjadi pada kelompok usia yang lebih tua. Prevalensi PAP meningkat secara tajam seiring bertambahnya usia dan memengaruhi sebagian besar populasi lanjut usia (>20\% pada individu beruisa lebih dari 80 tahun). ${ }^{4}$ Prevalensi PAP di Indonesia sebesar $9,7 \%$, yang didapatkan dari penelitian A Global Atherothrombosis Assessment (AGATHA) oleh American Society of Cardiology tahun $2006 .{ }^{5}$ Di antara satu juta orang Indonesia, didapatkan 13.807 menderita PAP. ${ }^{6}$ Penyakit arteri perifer jarang terdiagnosis sampai gejala yang diitmbulkan berat sehingga pasien PAP diposisikan sebagai kelompok yang butuh intervensi farmakoterapi. ${ }^{7}$ Populasi dewasa muda umumnya kurang memperhatikan faktor risiko sehingga perlu diberikan edukasi pencegahan penyakit yang berhubungan dengan gaya hidup.

Banyak penelitian observasional yang membuktikan bahwa risiko terjadinya myocardial infarction (MI), stroke, dan kehilangan anggota tubuh lebih sering pada individu dengan PAP yang merokok. ${ }^{3}$ Hubungan antara merokok dan PAP sudah diprediksikan sejak tahun 1991, diduga hubungan antara merokok dengan PAP lebih kuat dibandingkan hubungan merokok dengan PJK. $^{8}$ Laporan penelitian pernah menyebutkan bahwa PAP meningkat 3 kali pada pasien dengan riwayat merokok. ${ }^{9}$
Sampai saat ini belum didapatkan sumber ilmiah yang menyatakan bahwa obesitas mutlak menyebabkan terjadinya PAP, namun beberapa penelitian membuktikan banyak individu pada kelompok obesitas dengan nilai ABI tinggi. ${ }^{7}$ Berdasarkan data dari Dinas Kesehatan Provinsi Sulawesi Utara tahun 2015, terdapat $28,18 \%$ laki-laki obes dan $35,60 \%$ perempuan obes di seluruh Provinsi Sulawesi Utara. ${ }^{10}$ Studi epidemiologi yang dilakukan pada tahun 2016 di Amerika Serikat mendapatkan bahwa obesitas sentral yang memfokuskan pada waist hip ratio (dalam hal ini dinilai dari lingkar pinggang), berkaitan dengan risiko terjadinya PAP. ${ }^{11}$ Berdasarkan latar belakang yang telah diuraikan, maka penulis tertarik untuk mengetahui sejauh mana hubungan antara merokok dan obesitas sentral dengan nilai ABI pada mahasiswa Fakultas Kedokteran Universitas Sam Ratulangi (FK Unsrat) Manado.

\section{METODE PENELITIAN}

Penelitian ini dilakukan di FK Unsrat Manado. Jenis penelitian ialah analitik dengan desain studi potong lintang. Subyek penelitian ialah mahasiswa FK Unsrat. Variabel penelitian yaitu merokok, obesitas sentral, dan nilai ABI.

Penelitian ini telah mendapat persetujuan dari Komisi Etik Penelitian Kesehatan RSUP Prof. Dr. R. D. Kandou Manado, dengan nomor keterangan layak etik yaitu No. 048/EC/KEPK-KANDOU/X/2019.

\section{HASIL PENELITIAN}

Pada penelitian ini terdapat sebanyak 73 subyek; 26 yang tidak merokok dan tidak obes sentral, (36\%) 15 orang merokok $(20 \%), 21$ orang obes sentral $(29 \%)$, dan 11 orang merokok dan obes sentral $(15 \%)$.

Tabel 1 menunjukkan karakteristik subyek yang merupakan data hasil pengukuran subyek penelitian. Uji hubungan antara variabel merokok dan penurunan nilai ABI menggunakan uji Fisher's exact mendapatkan nilai $p=0,269 \quad(p>\alpha=0,05)$. 
Hal ini menunjukkan bahwa tidak terdapat hubungan bermakna antara merokok

Tabel 1. Karakteristik sampel

\begin{tabular}{lcccc}
\hline Variabel & N & Min-Mak & Rerata & $\begin{array}{c}\text { Simpangan } \\
\text { Baku }\end{array}$ \\
\hline Lingkar pinggang $(\mathrm{cm})$ & 73 & $63-121$ & 87,16 & 12,82 \\
ABI & 73 & $0,61-1,18$ & 0,95 & 0,12 \\
TDS (mmHg) & 73 & $90-150$ & 118,12 & 20,15 \\
TDD (mmHg) & 73 & $60-110$ & 80 & 11,47 \\
\hline
\end{tabular}

TDS, tekanan darah sistol; TDD, tekanan darah diaastol

dengan nilai ABI. Dari hasil uji odds ratio (OR) dengan uji Cochran's and MantelHaenszel antara subyek terpapar dan tidak terpapar rokok dengan nilai ABI didapatkan nilai OR 1,73. Hal ini berarti subyek yang merokok 1,73 kali lebih berisiko terjadi penurunan nilai ABI dibandingkan subyek yang tidak merokok.

Uji hubungan antara variabel obesitas sentral dengan nilai ABI menggunakan uji Fisher's exact mendapatkan nilai $\mathrm{p}=0,016$ $(\mathrm{p}<\alpha=0,05)$. Hal ini menunjukkan adanya hubungan bermakna antara obesitas sentral dengan nilai ABI. Dari hasil uji odds ratio (OR) dengan uji Cochran's and MantelHaenszel antara subyek terpapar dan tidak terpapar rokok dengan nilai ABI didapatkan nilai OR 4,53. Hal ini berarti subyek yang obes sentral 4,53 kali lebih berisiko terjadi penurunan nilai $\mathrm{ABI}$ dibandingkan subyek yang tidak obes sentral.

\section{BAHASAN}

Hasil analisis data melalui uji kemaknaan mendapatkan hubungan yang tidak bermakna $(p>\alpha)$ antara merokok dengan nilai ABI. Berbagai penelitian membuktikan bahwa merokok merupakan faktor risiko yang memiliki hubungan sangat kuat dan konsisten dengan PAP, namun pada penelitian ini tidak ditemukan hubungan bermakna secara statistik antara merokok dengan nilai ABI. Menurut penelitian yang dilakukan oleh Fowkes et al, ${ }^{14}$ merokok merupakan salah satu faktor pendukung terpenting dalam perkembangan terjadinya PAP dan orang merokok berisiko 2 kali lipat dibandingkan yang tidak merokok. Fowkes et $\mathrm{al}^{14}$ menyatakan bah- wa risiko tersebut akan berkurang jika berhenti merokok selama paling kurang 20 tahun. Pada penelitian ini usia subyek berkisar antara 18-23 tahun, telah menjadi perokok aktif sekitar 5-10 tahun sehingga belum menunjukan tanda dan gejala yang berarti (kekakuan arteri) akibat merokok. Bukan hanya PAP saja tetapi PAP yang asimtomatik juga berpeluang besar terjadi pada perokok, dalam hal ini khususnya perokok usia dewasa muda. Jumlah rokok yang dihabiskan perhari maupun akumulasi seumur hidup, berbanding lurus dengan risiko terjadinya PAP. ${ }^{14}$

Pada penelitian meta-analisis yang dilakukan di University of Glasgow tahun 2014, tim peneliti mencari hubungan aktif antara merokok dan PAP dengan membandingkan berbagai literatur. Mereka memiliki 3 kategori sampel penelitian; bukan perokok, mantan perokok, dan perokok, dan dari hasil analisis pertama didapatkan nilai $\mathrm{p}<0,05$ antara bukan perokok, mantan perokok, dan perokok. Kelompok perokok merupakan kelompok acuan, didapatkan risiko PAP menurun sedikit antara kelompok perokok dan mantan perokok, namun meningkat secara bermakna antara kelompok perokok dan bukan perokok. Dari berbagai studi yang membandingkan kategori mantan perokok dan perokok, hanya 2 studi yang menyimpulkan penurunan risiko PAP pada kelompok tersebut. Risiko tersebut menurun pada mereka yang sebelumnya telah berhenti merokok selama 20 tahun. Dari sejumlah studi yang dianalisis, hanya ada 1 studi yang kisaran usia sampel di atas 30 tahun, selain itu di atas 40 tahun. ${ }^{24}$ Hal tersebut berbeda jauh dengan 
penelitian ini dengan usia subyek mulai dari 18 tahun. Penelitian yang dilakukan Shu dan Santulli ${ }^{4}$ mendapatkan bahwa PAP sangat mudah ditemukan pada individu berisiko tinggi (prevalensi 29\%), yaitu yang berusia di atas 70 tahun tanpa faktor risiko tambahan, atau mereka yang berusia 50-69 tahun dengan riwayat merokok atau diabetes.

Pada penelitian yang dilakukan oleh Cacoubet $\mathrm{al}^{7}$ tahun 2009 mendapatkan nilai $\mathrm{p}<0,05$ atau hubungan bermakna antara merokok dengan PAP, dengan menambahkan usia dan jenis kelamin sebagai variabel bebas penelitian. Untuk merokok mereka definisikan sebagai jika merokok rata-rata 5 batang rokok per hari atau lebih selama paling tidak dalam sebulan terakhir sebelum penelitian dilakukan. ${ }^{7}$ Berbeda halnya dengan penelitian ini subyek dikatakan merokok jika menghabiskan 1 batang rokok dalam sehari tanpa batasan waktu tertentu.

Studi meta-analisis juga dilakukan oleh Doonan et al $^{13}$ yang meneliti efek merokok pada kekakuan arteri. Mereka mengelompokkan perokok akut, perokok kronik, perokok pasif, dan efek berhenti merokok. Perokok akut dan perokok kronik keduanya menunjukkan hubungan berarti secara statistik terhadap kekauan arteri, walau beberapa studi menyatakan hal ini hanya terjadi pada perempuan. Untuk perokok pasif, kekakuan arteri terlihat secara bermakna pada laki-laki, kelompok lanjut usia, dan yang dengan berat badan berlebih. $^{25}$

Pada penelitian ini, berdasarkan pengelompokkan subyek, jumlah yang obes sentral dan tidak obes sentral hampir seimbang (32 vs 41). Peneliti mengelompokkan subyek menjadi kelompok merokok berdasarkan pengukuran lingkar pinggang. Dari hasil analisis uji Fisher's exact didapatkan hubungan yang bermakna $(\mathrm{p}<\alpha)$ antara merokok dengan nilai ABI dengan odds ratio 4,53.

Berdasarkan penelitian yang dilakukan oleh Recio-Rodriguez et al, ${ }^{26}$ obesitas sentral (tanpa hipertensi dan DM) memiliki hubungan yang lebih erat dengan PAP dibandingkan obesitas berdasarkan IMT dan disarankan lebih baik lagi jika dilakukan pengukuran general adiposity. Banyak studi observasional yang membuktikan bahwa obesitas merupakan faktor risiko mayor terhadap PAP, namun tidak sedikit dari studi yang berkaitan dengan hipertensi dan DM, sehingga terdapat juga studi yang mendapatkan hubungan tidak konsisten antara obesitas dan penurunan ABI atau berhubungan jika obesitas disertai sindrom metabolik. ${ }^{26}$ Di sisi lain, sindrom metabolik tidak mungkin terdapat pada subyekl penelitian ini karena hipertensi, DM, dan kolesterolemia merupakan faktor eksklusi.

Penelitian Recio-Rodriguez et $\mathrm{al}^{26}$ juga menganalisis hubungan obesitas sentral dan obesitas terhadap kekakuan arteri. Mereka menggunakan perbandingan pulse wave velocity $(P W V)$, assessment of carotid intima-media thickness (C-IMT), dan ABI pada pasien DM, hipertensi, dan individu sehat sebagai kontrol. Terlepas dari DM dan hipertensi, mereka mendapatkan hasil bahwa hubungan obesitas sentral (pengukuran lingkar pinggang) dengan kekakuan arteri lebih erat dibandingkan hubungan obesitas (pengukuran IMT) dengan kekakuan arteri.

Pada penelitian Huang et $\mathrm{al}^{27}$ yang dilakukan di Shanghai, China, didapatkan persamaan dengan penelitian ini, yaitu menganalisis hubungan obesitas secara independen dengan PAP walau yang mereka gunakan yaitu IMT. Penelitian tersebut mendapatkan hubungan positif yang berbanding lurus antara obesitas dengan risiko PAP, namun usia minimum sampel 40 tahun. Batasan diagnosis menggunakan nilai $\mathrm{ABI}$ yaitu $\mathrm{ABI}<0,90$ atau nilai $\mathrm{ABI}>1,40$ dimana nilai-nilai tersebut sama dengan nilai yang digunakan pada penelitian ini. Mereka menemukan nilai kemaknaan yang lebih bermakna pada laki-laki dibandingkan perempuan.

Terdapat beberapa penelitian mengenai hubungan PAP dengan obesitas, namun sebuah penelitian studi potong lintang mengungkapkan hubungan positif yang bermakna yaitu waist-hip ratio (lingkar pinggang) dan prevalensi PAP tidak ada 
hubungan dengan IMT. Penelitian yang dilakukan oleh Wantania et $\mathrm{al}^{28}$ mendapatkan bahwa obesitas sentral memiliki korelasi dengan disfungsi endotel. Telah diketahui bahwa disfungsi endothel berperan penting dalam perkembangan PAP.

Salah satu kategori subyek penelitian ini laki-laki dewasa muda dengan obesitas sentral. Hal tersebut memiliki kemiripan variabel bebas dengan penelitian yang dilakukan Wowor $^{29}$ yang menggunakan hipertrofi ventrikel kiri sebagai variabel terikat dan menyimpulkan bahwa kebiasaan merokok pada laki-laki dewasa muda dengan obesitas sentral merupakan faktor risiko terjadinya pembesaran jantung kiri, walau tidak bermakna secara statistik. Mekanisme obesitas menyebabkan PAP mungkin mirip dengan mekanisme obesitas menyebabkan gangguan kardiovaskuler, namun keduanya memiliki profil tingkat risiko yang berbeda. ${ }^{17}$

\section{SIMPULAN}

Pada penelitian ini terdapat hubungan bermakna antara obesitas sentral dengan nilai $\mathrm{ABI}$, tetapi tidak terdapat hubungan bermakna antara merokok dengan nilai ABI.

Pada penelitian selanjutnya disarankan untuk memperjelas definisi merokok, atau lebih baik jika menggunakan kuesioner sehingga lebih mudah dikategorikan. Untuk variabel penelitian, dapat ditambahkan usia dan jenis kelamin.

\section{Konflik Kepentingan}

Penulis menyatakan tidak terdapat konflik kepentingan dalam studi ini.

\section{DAFTAR PUSTAKA}

1. Aboyans V, Criqui MH, Abraham P, Allison MA, Creager MA, Diehm C, et al. Measurement and interpretation of the ankle-brachial index: a scientific statement from the American Heart Association. Circulation. 2012; 126(24):2891.

2. Sutikno T, Panda AL, Wantania F. Perbandingan nilai ankle brachial index
(ABI) pada pria dewasa muda dengan asam urat normal dan asam urat tinggi. Jurnal Kedokteran Kesehatan. 2019; 1(1).

3. Dhaliwal G, Mukherjee D. Peripheral arterial disease: epidemiology, natural history, diagnosis and treatment. Int $\mathbf{J}$ Angiol. 2007;16(02):36.

4. Shu J, Santulli G. Update on peripheral artery disease: epidemiology and evidencebased facts. Atherosclerosis. 2018; 275:379-81.

5. Ankle Brachial Index Collaboration. Ankle brachial index combined with Framingham Risk Score to predict cardiovascular events and mortality: a meta-analysis. JAMA. 2008;300(2): 197.

6. Simatupang M, Pandelaki K, Panda AL. Hubungan antara penyakit arteri perifer dengan faktor risiko kardiovaskular pada pasien DM tipe 2. e-CliniC. 2013;1(1):7-12.

7. Cacoub PP, Abola MT, Baumgartner I, Bhatt DL, Creager MA, Liau CS, et al. Registry Investigators. Cardiovascular risk factor control and outcomes in peripheral artery disease patients in the reduction of atherothrombosis for continued health (REACH) registry. Atherosclerosis. 2009;204(2):e86-92.

8. Kemenkes RI. Riset Kesehatan Dasar; Riskesdas. Jakarta. Balitbang Kemenkes RI, 2018.

9. Norgren L, Hiatt WR, Dormandy JA, Nehler MR, Harris KA, Fowkes FG. Intersociety consensus for the management of peripheral arterial disease (TASC II). Journal of Vascular Surgery. 2007;45(1):S5-6.

10. Fowkes FG, Aboyans V, Fowkes FJ, McDermott MM, Sampson UK, Criqui MH. Peripheral artery disease: epidemiology and global perspectives. Nature Reviews Cardiology. 2017; 14(3):156.

11. Profil Kesehatan Provinsi Sulawesi Utara Tahun 2016 [database on the Internet]. Dinas Kesehatan Provinsi Sulawesi Utara, 2017.

12. Ng M, Freeman MK, Fleming TD, Robinson M, Dwyer-Lindgren L, Thomson B, et al. Smoking prevalence and cigarette consumption in 187 countries, 19802012. JAMA. 2014;311(2):185-9. 
13. Fowkes FG, Low LP, Tuta S, Kozak J. Ankle-brachial index and extent of atherothrombosis in 8891 patients with or at risk of vascular disease: results of the international AGATHA study. Eur Heart J. 2006;27(15):1862-4.

14. Lu JT, Creager MA. The relationship of cigarette smoking to peripheral arterial disease. Prog Biochem Biophys. 2004; 31(11):190-2.

15. Elks CM, Francis J. Central adiposity, systemic inflammation, and the metabolic syndrome. Curr Hypertens Rep. 2010;12(2):99-104.

16. Husnah H. Association of central obesity and waist/hip circumference with dislipidemia. World Nutrition Journal. 2018; 1(2):19.

17. Darvall KA, Sam RC, Silverman SH, Bradbury AW, Adam DJ. Obesity and thrombosis. Eur J Vasc Endovasc Surgery. 2007;33(2):224-30.

18. Sudoyo AW, Setiyohadi B, Alwi A, Simadibrata M, Setiati S, editors. Buku Ajar Ilmu Penyakit Dalam (4th ed). Jakarta: Departemen Ilmu Penyakit Dalam Fakultas Kedokteran Universitas Indonesia, 2006; p. 1688.

19. Santosa A, Listiono D. Prediksi score ankle brachial index (ABI) ditinjau dari tanda gejala peripheral arterial disease (PAD). Medisains. 2017;15(2):122-6.

20. Xu D, Li J, Zou L, Xu Y, Hu D, Pagoto SL, Ma Y. Sensitivity and specificity of the ankle - brachial index to diagnose peripheral artery disease: a structured review. Vascular Medicine. 2010; 15(5):363-367.

21. Criqui $\mathrm{MH}$, McClelland RL, McDermott $\mathrm{MM}$, Allison MA, Blumenthal RS, Aboyans V, et al. The ankle-brachial index and incident cardiovascular events in the MESA (Multi-Ethnic Study of Atherosclerosis). J Am Coll Cardiol. 2010;56(18):1507-10.

22. Allison MA, Hiatt WR, Hirsch AT, Coll JR, Criqui MH. A high ankle-brachial index is associated with increased cardiovascular disease morbidity and lower quality of life. J Am Coll Cardiol. 2008;51(13):1292-4.

23. Lin JS, Olson CM, Johnson ES, Whitlock EP. The ankle-brachial index for peripheral artery disease screening and cardiovascular disease prediction among asymptomatic adults: a systematic evidence review for the US Preventive Services Task Force. Ann Intern Med. 2013;159(5):335-7.

24. Lu L, Mackay DF, Pell JP. Meta-analysis of the association between cigarette smoking and peripheral arterial disease. Heart. 2014;100(5):414-23.

25. Doonan RJ, Hausvater A, Scallan C, Mikhailidis DP, Pilote L, Daskalopoulou SS. The effect of smoking on arterial stiffness. Hypertension Research. 2010;33(5):398.

26. Recio-Rodriguez JI, Gomez-Marcos MA, Patino-Alonso MC, Agudo-Conde C, Rodriguez-Sanchez E, Garcia-Ortiz L. Abdominal obesity vs general obesity for identifying arterial stiffness, subclinical atherosclerosis and wave reflection in healthy, diabetics and hypertensive. BMC Cardiovasc Dis. 2012;12(1):3.

27. Huang Y, Xu M, Xie L, Wang T, Huang X, Lv $X$, et al. Obesity and peripheral arterial disease: a Mendelian randomization analysis. Atherosclerosis. 2016 ;247:218-24.

28. Wantania F, Lefrandt RL, Pandelaki K. Adiponectin and tumor necrosis factor alpha levels, and their correlations with endothelial dysfunction in central obesity. Jurnal Biomedik. 2011;3(3): 179-85.

29. Wowor R. Hubungan antara kebiasaan merokok dan hipertrofi ventrikel kiri pada laki-laki dewasa muda dengan obesitas sentral. Jurnal Biomedik. 2018;10(3):174-9. 